\title{
INFLUENCE OF FLAKE SIZE ON THE MORPHOLOGY OF WET SPUN GRAPHENE OXIDE FIBERS
}

\author{
${ }^{1}$ Volkan ESKIZZEYBEK \\ ${ }^{1}$ Department of Materials Science and Engineering, Canakkale Onzekiz Mart University Turkey \\ ${ }^{1}$ veskizeybek@comu.edu.tr
}

(Geliş/Received:13.06.2017; Kabul/Accepted in Revised Form:20.07.2017)

\begin{abstract}
For using graphene in practical applications, it is crucial to transform the unique and individual properties of graphene flakes into ordered macroscopic materials. The physical and chemical properties of macroscale graphene structures are closely related to the size of graphene flakes as building blocks. However, the chemical methods adopted to synthesize graphene oxide (GO) flakes offer no tight control on the dimensionality of the ensuring flakes sizes. The goal of this study is to investigate morphological evaluation of graphene based fibers fabricated using building blocks with different average size.. A facile and effective centrifugation method was carried out for size sorting of graphene oxide flakes. Macroscopic graphene oxide fibers were continuously spun from graphene oxide/water suspensions followed by chemical and thermal reductions to obtain reduced graphene oxide fibers. All wet spinning parameters such as suspension concentration, injection rate and nozzle diameter were fixed to investigate the effect of average building block size on the structural morphology of the fibers. Microscopic investigations revealed that the flake size have an enormous impact on the morphology of graphene oxide fibers. The increased average flake size results in the fibers with rectangular-like cross-section and increased amount of voids within the graphene oxide fiber.
\end{abstract}

Key Words: Centrifugation, Colloid, Dimensional control, Graphene oxide, Image processing

\section{Grafen Oksit Kabukların Boyutlarına Göre Sınıflandırılması: Deneysel Çalışma}

ÖZ: Pratik uygulamalarda grafen kullanmak için grafen kabukların eşsiz ve münferit özelliklerinin makroskopik, düzenli malzemelere dönüştürülmesi çok önemlidir. Makro boyuttaki grafen yapıların fiziksel ve kimyasal özellikleri, bu yapıları oluşturan yapıtaşları olan grafen kabukların boyutları ile yakından ilgilidir. Bununla birlikte, kimyasal yöntemler kullanılarak üretilen grafen oksit (GO) kabuklarının boyutları istenilen aralıklarda kontrol edilememektedir. Bu çalışmanın amacı, farklı ortalama boyutlara sahip grafen kabuklar kullanılarak üretilen grafen esaslı fiberlerin morfolojik değerlendirmesini araştırmaktır. Grafen oksit kabukların boyut sıralanması için basit ve efektif bir santrifüj yöntemi uygulanmıştır. Makroskopik grafen oksit fiberleri, grafen oksit/su süspansiyonlarının sürekli olarak eğrilmesi ile üretilmiş bunu takiben indirgenmiş grafen oksit elyafı elde etmek için kimyasal ve termal indirgeme işlemleri yapılmıştır. Süspansiyon konsantrasyonu, enjeksiyon hızı ve orifis çapı gibi tüm ıslak eğirme parametreleri sabit tutularak, yanlızca grafen kabuk boyutunun fiberlerin yapısal morfolojisine etkisi araştırılmıştır. Mikroskopik incelemeler kabuk boyutunun, grafen oksit fiberlerin morfolojisi üzerinde çok büyük bir etkisi olduğunu ortaya koymuştur. Artan ortalama kabuk boyutu, grafen oksit fiberlerin kesitinin dikdörtgen geometrisine benzemesine ve fiber içerisindeki boşlukların artmasına neden olmuştur. 


\section{INTRODUCTION}

Graphene is a planar monolayer of carbon atoms that arranged into a two-dimensional honeycomb lattice with sp ${ }^{2}$ hybridized bonds (Esmaeili and Entezari, 2014). The unique $\pi$-conjugation in graphene endows extraordinary mechanical, thermal and electrical properties which attract great scientific attention of many theoretical and experimental studies during recent years in various fields such as energy storage (Tong et al., 2011), electronic devices (Li et al., 2013) and nanocomposites (Zhuo et al., 2013). As a consequence, various graphene based structures in nano-, micro- and macro-scale have been synthesized and characterized, including 2D graphene papers (Chen et al., 2008) and 1D graphene fibers (Xu and Gao, 2011; Cheng et al., 2013).

The size of the building blocks fundamentally governs physical performances of the macro-scale graphene based structures since larger building blocks usually yields better mechanical and electrical properties up to three-fold increase (Chae and Kumar, 2008; Xiang et al., 2013). However, the difficulty of producing high quality graphene flakes with controlled size and chemical composition still remain as a challenge especially in scalable industrial processes. Chemical exfoliation of graphite with strong acid treatment, a method introduced by Hummers and Brodie, one of the most preferred production method to generate graphene oxide (GO) flakes (Allen et al., 2010). GO flakes exhibit good dispersion in water and other commonly used solvents to form liquid crystal phases due to existence of epoxy and hydroxyl groups formed in the basal plane and carbonyl and carboxylic acid groups in the edge sites (Aboutalebi et al., 2011). However, the oxidation and exfoliation processes of the graphite results diverse sizes of GO flakes. Therefore, the separation of the graphene based flakes with well-defined size is of importance for the accurate control of the macro-scale mechanical and electrical properties of the graphene based structures (Pan and Aksay, 2011).

Controlling the size of particles is a key parameter to tailor the physical and chemical properties. For example, the chemical and physical properties of nanoscale particles are significantly influenced by their size. Centrifugal separation process is a simple physical method used for size sorting of nano-scale materials distributed in liquid medium. The main outcome of the centrifugal separation is that no additional chemical is added into the solution for size sorting, and thus the physical and chemical properties of the particles in the solution are preserved. Although centrifugal dimensional sorting process is defined for spherical particles according to the Stoke law, it can also be utilized to particles with anisotropic morphology such as carbon nanotubes (CNTs), and DNA (Tirado et al., 1984; Arnold et al., 2008; Batista et al., 2014). Recently, centrifugation process has been utilized generally as a post-synthesis size sorting approach including GO flakes (Khan et al., 2012; Bonaccorso et al., 2013; Han et al., 2013). Since centrifugation time and rotational speed are the correlated parameters to control particle size during sedimentation, it must be adressed their relationship specifically to sort GO flakes with specific size ranges. Khan et al. (Khan et al., 2012) described a centrifugal separation method to separate an existing dispersion of small graphene flakes in N-methyl pyrrolidone solvent with mean flake length of $\sim 1 \mu \mathrm{m}$ into fractions and low concentrations. They fixed the centrifugation time as $45 \mathrm{~min}$ while altering the rotational speeds from 4000 to $500 \mathrm{rpm}$. However, it is need to be adressed quantatively those of parameters for larger flake sizes distributed in aqueous medium. With this motivation, our group recently demostrated the viability of centrifugation process for size selection of GO flakes of diameters up to $40 \mu \mathrm{m}$ using distilled aqueous medium without the need to use of chemical additives or other solutes (Özçakır et al., 2016; Özçakır and Eskizeybek, 2016).

The development of high-performance graphene based fibers (GBFs) could inspire more engineering applications of graphene. GBFs possess lots of advantages over traditional carbon fibers and newly developed carbon-nanotube (CNT) fibers, especially in terms of their simple processing conditions and cost effective production. GBFs can play an important role in the production of textiles, especially wearable energy storage, or other two- or three-dimensional macroscopic structures (Xu and Gao, 2011; Cong et al., 
2012; Dong et al., 2012). However, the nature and importance of the fiber building blocks have not been fully described, and the relationship between the building blocks and fiber properties also needs to be further clarified. The most effective and scalable process to produce graphene fiber from graphene oxide flakes is wet spinning. In this process, graphene oxide particles are dispersed in distilled water and this spinning dope is injected into a rotating coagulation bath. The most important parameters of wet spinning process are concentration of spinning dope, viscosity of coagulation bath, needle size, and injection rate (Xu and Gao, 2014).

In this study, the effect of building block size on the morphology of wet spun graphene based fibers was reported. For this purpose, a centrifugal sedimentation process was utilized to sort graphene oxide flakes with controllable average sizes. The centrifugation times for the specific size ranges were calculated based on Stokes' law to separate GO flakes from homogenously distributed aqueous medium. Then, the sorted graphene flakes were used as spinning dopes to prepare wet-spun graphene fibers. The morphologies of the macroscopic fibers were examined using scanning electron microscopy. A possible fiber formation mechanism was introduced depending on the different spinning dopes with different average flake sizes.

\section{MATERIAL AND METHOD}

\section{Separation of GO Flakes with Centrifugation Process}

Our initial experiments relied on simple sedimentation centrifugation. An empirical model developed by Walter et al. (Walter et al., 2015) was utilized to sort GO flakes in specific size ranges. The developed model is expressed in the following formula:

$$
R C F=\frac{w^{2} r}{g}=\frac{18 \eta l\left(\frac{f t}{f 0}\right)}{g t\left(\rho_{G O}-\rho_{C}\right)}\left(\frac{3 h^{3}}{2 q^{2}}\right)^{-\frac{2}{3}}
$$

In Eq (1) relative centrifugal force (RCF) is a function of the rotational speed and the sample position in the rotor normalized by the gravitational field of the earth which is typically utilized to compare centrifugal forces created by centrifuges with different geometry, $w$ is angular velocity $(\mathrm{rad} / \mathrm{s}), r$ is the radial position from the axes of rotation within the centrifuge $(\mathrm{m}), h$ is the single layer GO flake height $(\mathrm{m}), g$ is the gravitational acceleration, $l$ is the length of the centrifuge tube; $t$ is the experimental time, $q$ is the aspect ratio which is the height $h$ (1.5 $\mathrm{nm}$ for graphene oxide layer) divided by the hydrodynamic diameter $d$ of GO flakes, $\eta$ is the viscosity of solution (Pa.sn), QGO is the density of GO flakes $\left(\mathrm{kg} / \mathrm{m}^{3}\right)$, and QC is the density of solution $\left(\mathrm{kg} / \mathrm{m}^{3}\right)$. In addition, $f_{t} / f_{0}$ is the translational friction coefficient of disk like particles which is calculated as follows;

$$
\frac{f_{t}}{f_{0}}=1.0408+0.0197 k+0.07255 k^{2}+0.00303 k^{3}+0.00123 k^{4}+8.22 E^{-5} k^{5}+6.44 E^{-6} k^{6}
$$

In Eq. (2) $k$ is defined as $k=\ln (q)$. Other terms used to calculate centrifugation times are given in Table 1.

The centrifugation times according to Eq. (1) for fixed GO flake size ranges and rotational speeds were calculated and represented in Figure 1. The GO flakes were assumed as single layer with the height of 1.3 $\mathrm{nm}$ and the hydrodynamic diameters were selected between 5 to $15 \mu \mathrm{m}$. 
Table 1. Typical terms used to calculate centrifugation times for specific GO flake

\begin{tabular}{|c|c|c|}
\hline Symbol & Definition & Value \\
\hline$l$ & Length of the centrifuge tube $(\mathrm{m})$ & 0.08 \\
\hline$\eta$ & Viscosity of water $\left(20^{\circ} \mathrm{C}\right)($ Pa.s $)$ & $1.002 \times 10^{-3}$ \\
\hline$d$ & $\begin{array}{l}\text { Hydrodynamic diameter of GO flakes } \\
\qquad(\mathrm{m})\end{array}$ & $5 \times 10^{-6}-10 \times 10^{-6}-15 \times 10^{-6}-20 \times 10^{-6}-25 \times 10^{-6}-30 \times 10^{-6}-35 \times 10^{-6}$ \\
\hline$\rho_{G O}$ & Density of GO flakes $\left(\mathrm{g} / \mathrm{cm}^{3}\right)$ & $1.8\left(20^{\circ} \mathrm{C}\right)$ \\
\hline$\rho_{C}$ & Density of water $\left(\mathrm{g} / \mathrm{cm}^{3}\right)$ & $1.0\left(20^{\circ} \mathrm{C}\right)$ \\
\hline$R$ & Radius of rotation $(\mathrm{m})$ & 0.086 \\
\hline \multirow[t]{5}{*}{$w$} & Angular velocity (rad.s ${ }^{-1}$ ) & 6000 RPM (628.319 rad.s s $\left.^{-1}\right)$ \\
\hline & & 5000 RPM (523.599 rad.s s $\left.^{-1}\right)$ \\
\hline & & 4000 RPM (418.879 rad.s s $\left.^{-1}\right)$ \\
\hline & & 3000 RPM (314.159 rad.s s $\left.^{-1}\right)$ \\
\hline & & 2000 RPM (209.440 rad.s r $\left.^{-1}\right)$ \\
\hline
\end{tabular}

GO flakes were purchased from Graphene Supermarket, USA (single layer flake content >97\%) with flake sizes up to $40 \mu \mathrm{m}$. The centrifugation process was described in our previous works in detail (Özçakır et al., 2016; Özçakır and Eskizeybek, 2016). Briefly, $1 \mathrm{mg} \mathrm{mL}^{-1}$ of aqueous GO solution was prepared effectively by aid of sonication and magnetic stirring, respectively. Following, centrifugation process was utilized to separate GO flakes with specific sizes. Hettich EBA 20 centrifuge with a rotor radius $86 \mathrm{~mm}$ and a maximum rotational speed of $6000 \mathrm{rpm}$ was used during centrifugation process. Note that, it takes approximately $30 \mathrm{~s}$ to accelerate centrifuge rotor and slow down and this time is not included into the calculated separation times. After separation, the supernatant solution was dried in a silicon mold at $60^{\circ} \mathrm{C}$ for $4 \mathrm{~h}$ under vacuum conditions for further use. The typical separation process of GO flakes with specific size ranges is schematically illustrated in Figure 1. The separation process was utilized successively to sort GO flakes with different average diameters by changing centrifugation speed and time. The resulting size sorted GO flakes were grouped into four groups including sediment as the remaining GO flakes after centrifugal sorting process.

The particle size distributions of the GO flakes were revealed by measuring the surface area of more than 3000 flakes by means of electron microscopy. Following, the measured surface area was transformed into hydrodynamic diameter using image processing with Image $\mathrm{J}^{\circledR}$.

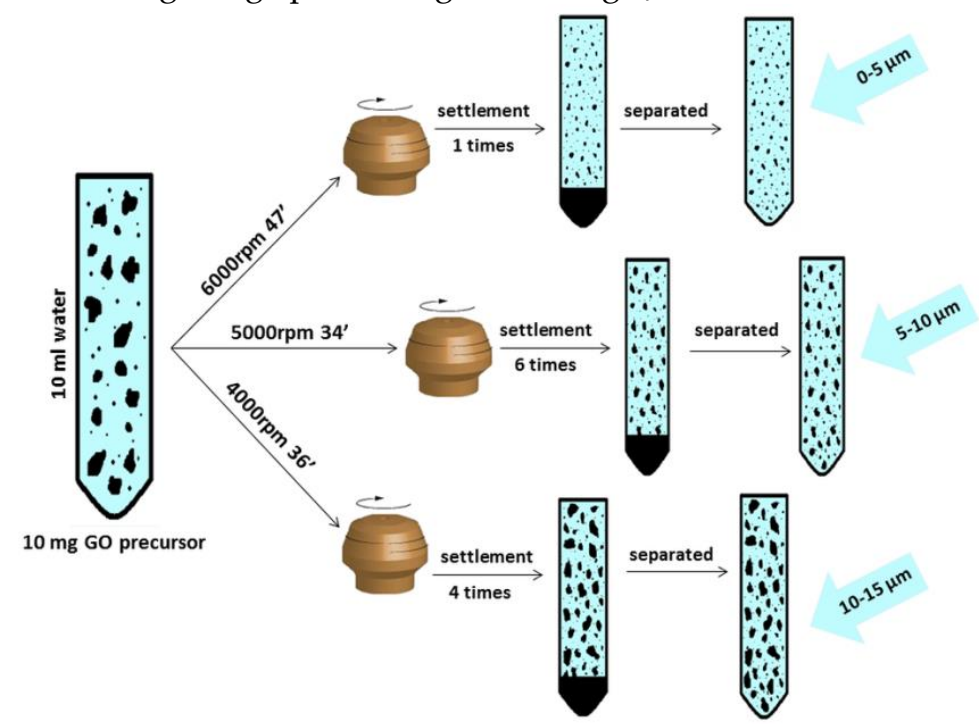

Figure 1. Schematic representation of the centrifugation process utilized to separate GO flakes with specific sizes 


\section{Wet Spinning of Graphene Oxide Fibers}

Size sorted GO flakes with different average flake sizes were well dispersed in DI water. The computer controlled wet spinning unit was utilized to spun graphene fibers. The GO colloids $\left(12 \mathrm{mg} \mathrm{mL}^{-1}\right)$ were injected through a blunt-tipped needle with $210 \mu \mathrm{m}$ inner diameter at the rate of $0.5 \mathrm{~mL} / \mathrm{min}$ into a rotating (15 rpm) aqueous chitosan ( $\mathrm{M}_{\mathrm{w}}=600.000-800.000$, Acros Organics) coagulation bath $(1 \mathrm{wt} \%)$. The GO gel-state fiber formed immediately when met with the bath. The GO preparation steps were schematically illustrated in Figure 2. Note that no tension was applied during forming of the macroscopic fibers. After been soaked for $20 \mathrm{~min}$ in the coagulation bath, the GO fibers (GOFs) was extracted, rinsed with de-ionized water, and dried on a water absorbing paper overnight. The centrifugal seperated GO flakes with different avarage sizes were used as spinning dopes to prepare GOFs, therefore three types of GOFs were fabricated.

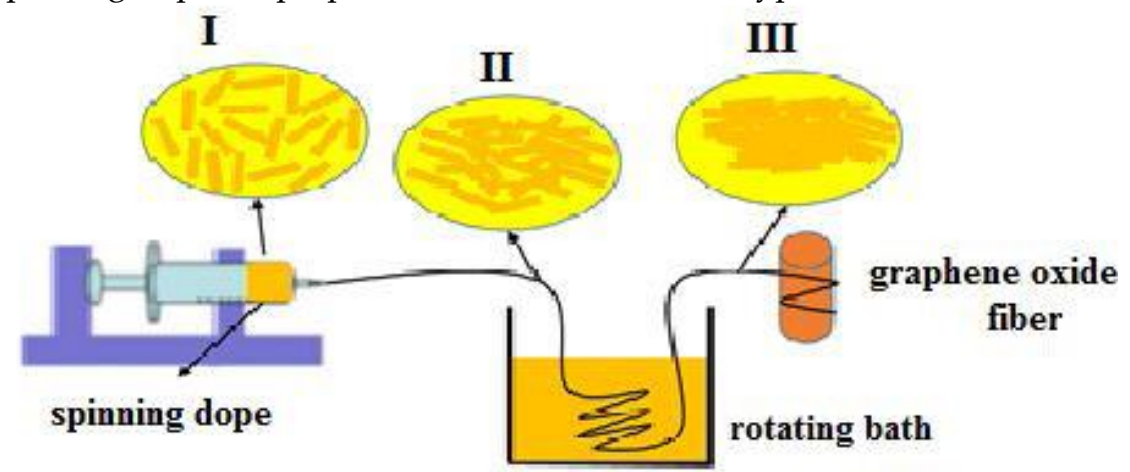

Figure 2. Schematic representation of wet-spinning process

\section{Characterization}

The resulting graphene flakes and GOFs were monitored using scanning electron microscopy (JEOL SEM-7100-EDX). At least ten SEM images were recorded from different areas of the deposited graphene flake samples on Si wafer, and image processing was applied to measure their areas. Assuming GO flakes are disclike, the GO flake effective diameters were calculated from at least 3000 GO flakes.

\section{RESULTS AND DISCUSSIONS}

The rational speed and the centrifugation time are crucial parameters for size sorting of GO flakes. In particular, by increasing the rational speed and reducing the centrifugation time, the amount of sediment increases: by centrifugation either at $6000 \mathrm{rpm}$ for $47 \mathrm{~min}$, at $5000 \mathrm{rpm}$ for $34 \mathrm{~min}$, and at 4000 $\mathrm{rpm}$ for $36 \mathrm{~min}$, it is obtained 6.15, 8.74 and $11.97 \mu \mathrm{m}$ of the average GO flake sizes as shown in Figure 3a, respectively. Note that GO flakes smaller than $5 \mu \mathrm{m}$ were observed in all SEM images taken after second and third step of centrifugation process (Figure 3b-d). This is attributed to brake of large GO flakes during preparing GO sediments for next separation process. It is known that bath-sonication mixing of GO flakes results decreasing sizes and consequently decreases the average flake size of the sediment. Therefore, we applied bath-sonication to disperse GO sediment in water for $5 \mathrm{~min}$ to minimize damage and following mixed with vortex shaker for $2 \mathrm{~min}$. The average size of GO flake sediment at the bottom of the tube is measured as $17 \mu \mathrm{m}$. This proves the effectiveness of selective centrifugation for GO flake size sorting, while requiring low centrifugal fields, achievable with ordinary benchtop centrifuges. The size sorted GO flakes with different average effective diameters were used as spinning dopes to fabricate three types of GOFs. The fabricated GOFs were named as SGOFs, LGOFs 
and HGOFs based on the used spinning dopes 6.15, 11.97 and sediment with the efficient diameter $17 \mu \mathrm{m}$, respectively.
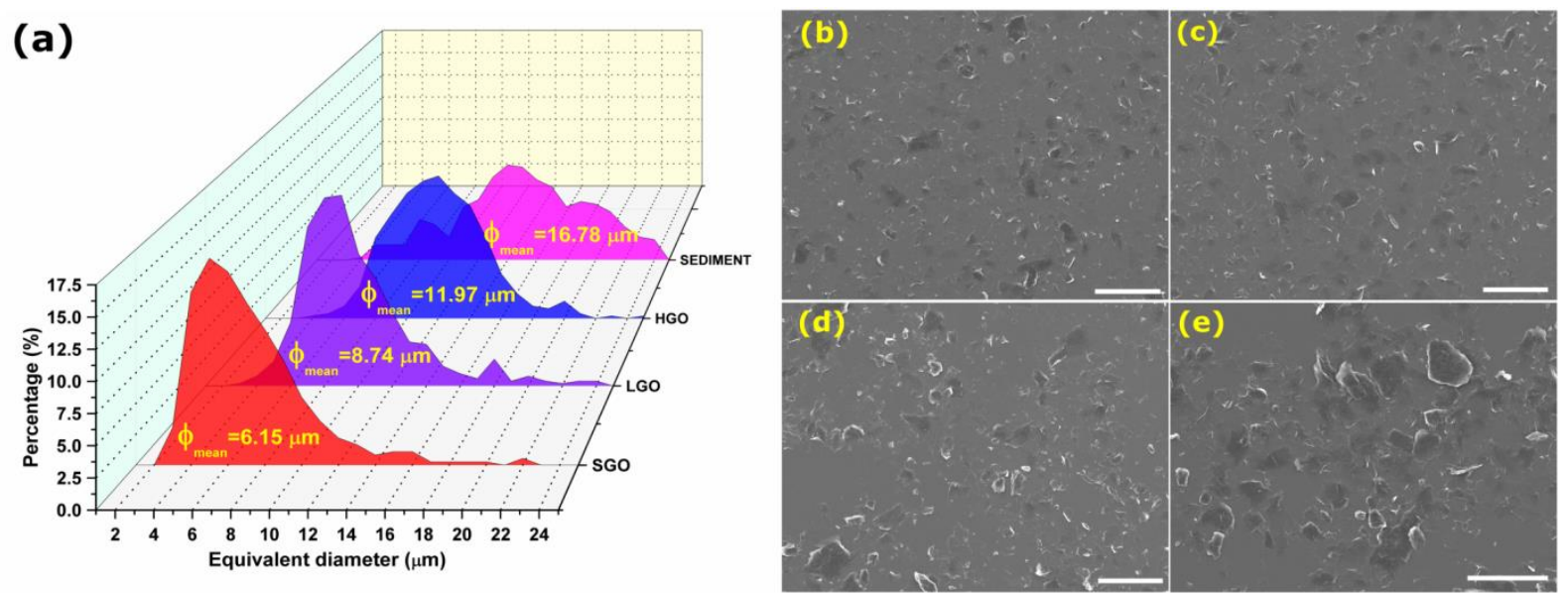

Figure 3. a) The average flake size distribution of separated GO supernatants and corresponding SEM images selected from image processing of the flakes (scale bars $10 \mu \mathrm{m}$ ), b) $6000 \mathrm{rpm} 47 \mathrm{~min}, \mathrm{c}) 5000 \mathrm{rpm} 34$ min, d) $4000 \mathrm{rpm} 36 \mathrm{~min}, \mathrm{e})$ the sediment of graphene oxide flakes

The morphologies of GOFs could likely have an enormous impact on their physical features such as mechanical properties. The corrugated surface and cross sections of the fabricated GOFs were examined in detail by SEM analysis as shown in Figure 4. In general, all types of GOFs represent non-uniform axial morphology with wrinkles along the fiber axis. The surfaces of the fibers are rough and no droplets are observed in the fibers. In addition, the cross-sections of the fibers are not regular. The SGOFs were produced using the smallest GO flakes in average effective diameters. It is apparent that the SGOFs have lowest average diameters and the smallest cross-sectional areas with respect to LGOFs and HGOFs. Further, diameters of the fibers were also measured along the axis from different areas; thereby average diameters of the fibers were calculated. Based on our measurements, the average diameters of SGOFs are measured as $65 \pm 25 \mu \mathrm{m}$ (Figure 4a). The cross sections of the SGOFs exhibit the closest morphology to the circular section while the section is composed of tightly packed GO layers, and rare voids are observed in the fiber (Figure 4d). LGOFs were prepared using GO flakes with an average effective diameter of $\sim 12 \mu \mathrm{m}$. The surfaces of LGOFs represent increased roughness with respect to SGOFs and no droplet formation is observed in the fibers. The mean diameter of LGOFs is measured as $84 \pm 30 \mu \mathrm{m}$ and average cross-sectional areas of LGOFs are evaluated to be larger than the SGOFs (Figure $4 \mathrm{~b}$ ). The cross-sections of LGOFs have a star-like morphology with more indentations and protrusions than SGOFs. Further, it has been determined that the cross-section is composed of the tightly packed GO layers, and the amount of voids between the GO layers is increased with respect to SGOFs (Figure 4e). The HGOFs were produced using GO flakes of sediment with an average effective diameter $\sim 17 \mu \mathrm{m}$. The fibers have the highest surface roughness and without any droplet formation. The cross-sections of the HGOFs have mostly rectangular-like morphologies, but with more indentations and protrusions. The mean diameters HGOFs are measured as $105 \pm 20 \mu \mathrm{m}$ and their average cross-sectional areas are evaluated to be larger than the LGOFs (Figure 4c). However, it is observed that the amount of voids between the GO layers is at the highest level with respect to SGOFs and LGOFs (Figure 4f).

The enormous morphological differences are clearly originated from the contribution of average flake size as building blocks within the fiber and rapid liquid changes during gelation stage of the fiber since the GO colloid enters the coagulation bath. In the case of using larger GO flakes to prepare GO/water 
dispersions, the amount of trapped water between the flakes increases. Thereby, larger GOFs with irregular cross-sections are formed. During the drying process namely densification or dehydration, the resulting fibers shrink more and try to fill the gaps due to the evaporation of the solvent trapped in between ordered GO flakes (Xu et al., 2013). As a result, the surface of fiber becomes wrinkled aligned with the fiber axis and the cross section also approaches a rectangle rather than a circular one with increasing GO flake sizes. Xiang et al. (Xiang et al., 2013) noted that the non-uniform morphology of fibers varies with the GO dimension and the fiber sections were obtained more circular when the dimensions of the GO flakes were lowered to $100 \mathrm{~nm}$. This means that the small size GO flakes can easily fill the voids formed during dehydration and the cross section looks more uniformly circular.

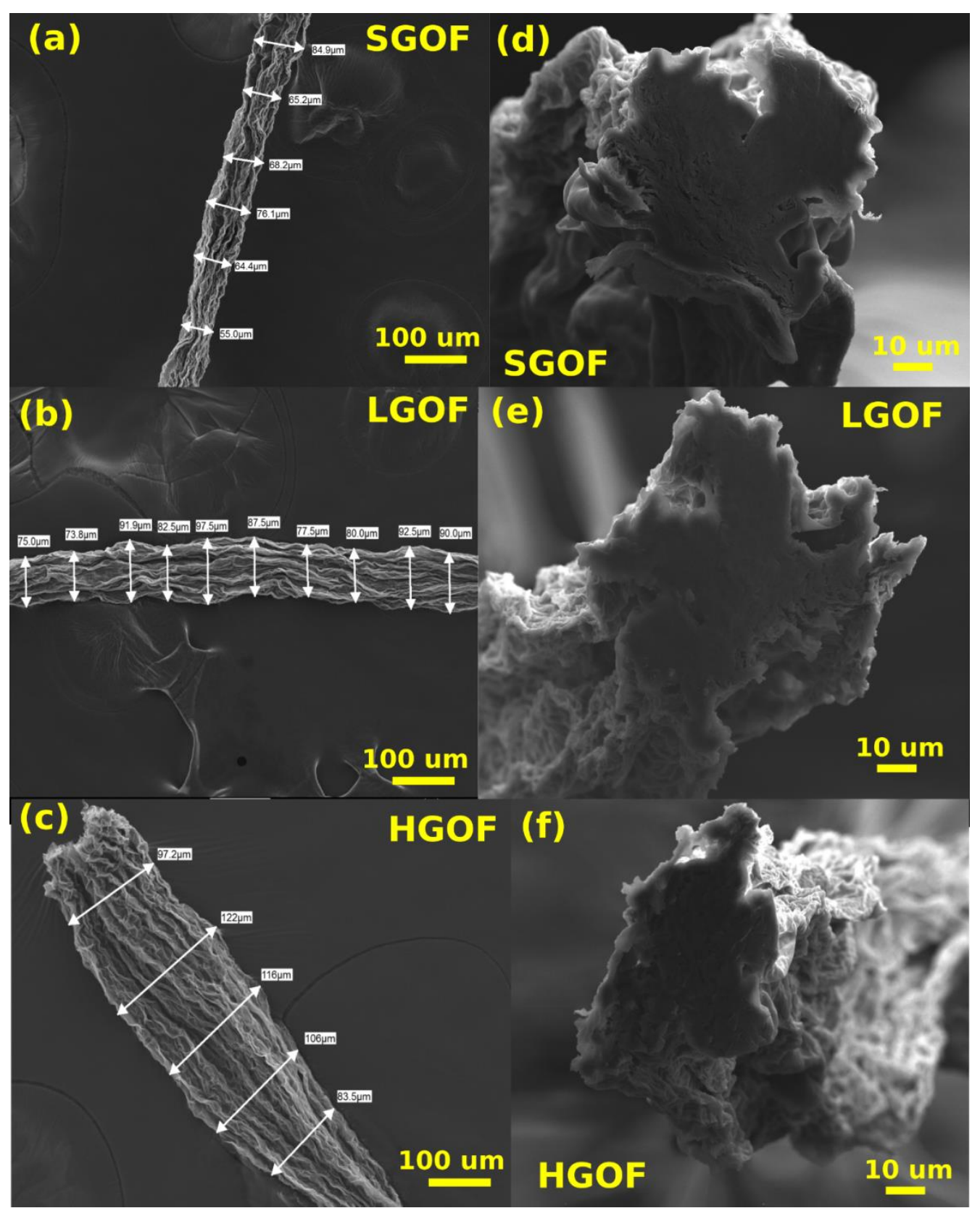

Figure 4. Typical SEM images of (a-c) the surface and (d-f) the cross-section of GOF produced by wet bending method. (a, d) SGOF (b, e) LGOFs (c, e ) HGOFs 
The relationship between the production of GOF in different surface and cross-sectional morphologies and the relationship of the GO sheet size is schematically illustrated in Figure 5. The voids in the fiber are due to the high mass transfer rate difference between the pure water in the colloid and the chitosan. However, these voids were reduced by washing with ethanol and drying processes due to the re-orientation of GO flakes and stacking closer to each other. It is confidentially believed that the small size GO flakes slip efficiently into these voids during fiber shrinkage in radial direction, therefore the average diameters of the SGOFs are smaller compared to LGOFs and HGOFs. Thus, the resulting SGOFs are produced with higher stacking density and flake orientation along the fiber axis. In the case of using GO flakes with larger average sizes, the slipping is limited within the fiber due to the friction between the flakes, so that the GO flakes are wrinkled and bent. Furthermore, since lager GO flakes cannot sufficiently slip into the voids, they cannot fill the voids which are clearly visible in the SEM images. The voids in GOFs can be thought of as nanoscale defects in the layers or microscopic voids. It is well known that these defects lead the fibers to break at lower tensile strengths and thus worsen their mechanical properties. On the other hand, the sheet boundaries decrease with the increasing average size of the GO flakes, and, as a result, the fibers withstand higher loads due to the improvement in the transfer of forces between the flakes. In addition, due to the increased contact between the bending of large-sized flakes, mechanical interlocking increase and larger forces are required to move the flakes over each other.

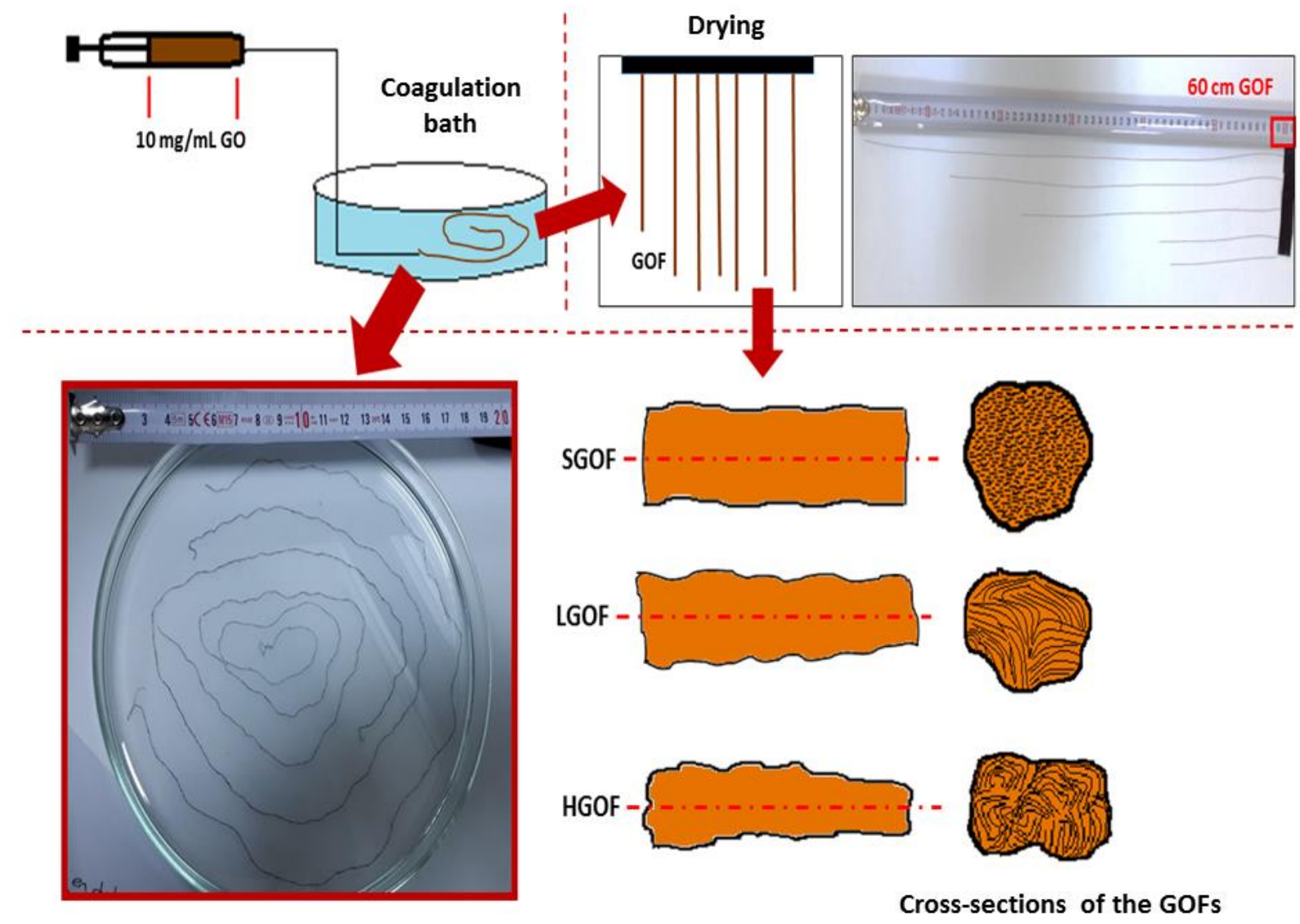

Figure 5. Schematic representation of the effect of GO flake size on fiber morphology in GOFs 


\section{CONCLUSION}

Graphene flakes with different average flake sizes were spun to fabricate macroscopic fibers with controllable physical properties. A facile and effective gradient centrifugation process was utilized for size sorting of graphene oxide flakes. Macroscopic graphene oxide fibers were continuously spun from graphene oxide/water suspensions. The surface morphology of the GO fibers was not smooth; moreover, the surface roughness increases with increasing flake sizes. The voids with the fiber were formed during drying process and the average flake size governs the amount of voids as larger flakes increase voids within the GOFs.

\section{ACKNOWLEDGEMENTS}

This study was supported by The Scientific and Technological Research Council of Turkey (TUBITAK) under grant no. MAG-214M650.

\section{REFERENCES}

Aboutalebi, S.H., Gudarzi, M.M., Zheng, Q.B., Kim, J.K., 2011, "Spontaneous Formation of Liquid Crystals in Ultralarge Graphene Oxide Dispersions", Advanced Functional Materials, Vol. 21, pp. 2978-2988.

Allen, M.J., Tung, V.C., Kaner, R.B., 2010, "Honeycomb Carbon: A Review of Graphene", Chemical Reviews, Vol. 110, pp. 132-145.

Arnold, M.S., Suntivich, J., Stupp, S.I., Hersam, M.C., 2008, "Hydrodynamic Characterization of Surfactant Encapsulated Carbon Nanotubes Using an Analytical Ultracentrifuge", Acs Nano, Vol. 2, pp. 22912300.

Batista, C.A.S., Zheng, M., Khripin, C.Y., Tu, X.M., Fagan, J.A., 2014, "Rod Hydrodynamics and Length Distributions of Single-Wall Carbon Nanotubes Using Analytical Ultracentrifugation", Langmuir, Vol. 30, pp. 4895-4904.

Bonaccorso, F., Zerbetto, M., Ferrari, A.C., Amendola, V., 2013, "Sorting Nanoparticles by Centrifugal Fields in Clean Media", Journal of Physical Chemistry C, Vol. 117, pp. 13217-13229.

Chae, H.G., Kumar, S., 2008, "Materials science - Making Strong Fibers", Science, Vol. 319, pp. 908-909.

Chen, H., Muller, M.B., Gilmore, K.J., Wallace, G.G., Li, D., 2008, "Mechanically Strong, Electrically Conductive, and Biocompatible Graphene Paper", Advanced Materials, Vol. 20, pp. 3557-+.

Cheng, H.H., Dong, Z.L., Hu, C.G., Zhao, Y., Hu, Y., Qu, L.T., Chena, N., Dai, L.M., 2013, "Textile Electrodes Woven by Carbon Nanotube-Graphene Hybrid Fibers for Flexible Electrochemical Capacitors", Nanoscale, Vol. 5, pp. 3428-3434.

Cong, H.P., Ren, X.C., Wang, P., Yu, S.H., 2012, "Wet-Spinning Assembly of Continuous, Neat, and Macroscopic Graphene Fibers", Scientific Reports, Vol. 2, pp.

Dong, Z.L., Jiang, C.C., Cheng, H.H., Zhao, Y., Shi, G.Q., Jiang, L., Qu, L.T., 2012, "Facile Fabrication of Light, Flexible and Multifunctional Graphene Fibers", Advanced Materials, Vol. 24, pp. 1856-1861.

Esmaeili, A., Entezari, M.H., 2014, "Facile and Fast Synthesis of Graphene Oxide Nanosheets via Bath Ultrasonic Irradiation", Journal of Colloid and Interface Science, Vol. 432, pp. 19-25.

Han, J.T., Jang, J.I., Kim, S.H., Jeong, S.Y., Jeong, H.J., Lee, G.W., 2013, "Size Sorting of Chemically Modified Graphene Nanoplatelets", Carbon Letters, Vol. 14, pp. 89-93.

Khan, U., O'Neill, A., Porwal, H., May, P., Nawaz, K., Coleman, J.N., 2012, "Size selection of dispersed, exfoliated graphene flakes by controlled centrifugation", Carbon, Vol. 50, pp. 470-475. 
Li, X.M., Zhao, T.S., Chen, Q., Li, P.X., Wang, K.L., Zhong, M.L., Wei, J.Q., Wu, D.H., Wei, B.Q., Zhu, H.W., 2013, "Flexible All Solid-State Supercapacitors Based on Chemical Vapor Deposition Derived Graphene Fibers", Physical Chemistry Chemical Physics, Vol. 15, pp. 17752-17757.

Özçakır, E., Ballı, B., Eskizeybek, V., 2016, "Fabrication of Macroscale Graphene Fibers via Wet Spinning", Proceedings of ISER International Conference, Vol. Barcelona, Spain, 16 May 2016, pp.

Özçakır, E., Eskizeybek, V., 2016, "A Facile and Effective Method for Size Sorting of Large Flake Graphene Oxide ", Proceedings of the World Congress on Recent Advances in Nanotechnology (RAN'16), Vol. Prague, Czech Republic - April 1 - 2, 2016, pp.

Pan, S.Y., Aksay, I.A., 2011, "Factors Controlling the Size of Graphene Oxide Sheets Produced via the Graphite Oxide Route", Acs Nano, Vol. 5, pp. 4073-4083.

Tirado, M.M., Martinez, C.L., Delatorre, J.G., 1984, "Comparison of Theories for the Translational and Rotational Diffusion-Coefficients of Rod-Like Macromolecules - Application to Short DNA Fragments", Journal of Chemical Physics, Vol. 81, pp. 2047-2052.

Tong, X., Wang, H., Wang, G., Wan, L.J., Ren, Z.Y., Bai, J.T., Bai, J.B., 2011, "Controllable Synthesis of Graphene Sheets with Different Numbers of Layers and Effect of the Number of Graphene Layers on the Specific Capacity of Anode Material in Lithium-ion Batteries", Journal of Solid State Chemistry, Vol. 184, pp. 982-989.

Walter, J., Nacken, T.J., Damm, C., Thajudeen, T., Eigler, S., Peukert, W., 2015, "Determination of the Lateral Dimension of Graphene Oxide Nanosheets Using Analytical Ultracentrifugation", Small, Vol. 11, pp. 814-825.

Xiang, C.S., Young, C.C., Wang, X., Yan, Z., Hwang, C.C., Cerioti, G., Lin, J., Kono, J., Pasquali, M., Tour, J.M., 2013, "Large Flake Graphene Oxide Fibers with Unconventional 100\% Knot Efficiency and Highly Aligned Small Flake Graphene Oxide Fibers", Advanced Materials, Vol. 25, pp. 4592-4597.

Xu, Z., Gao, C., 2011, "Graphene Chiral Liquid Crystals and Macroscopic Assembled Fibres", Nature Communications, Vol. 2, pp.

Xu, Z., Gao, C., 2014, "Graphene in Macroscopic Order: Liquid Crystals and Wet-Spun Fibers", Accounts of Chemical Research, Vol. 47, pp. 1267-1276.

Xu, Z., Liu, Z., Sun, H.Y., Gao, C., 2013, "Highly Electrically Conductive Ag-Doped Graphene Fibers as Stretchable Conductors", Advanced Materials, Vol. 25, pp. 3249-3253.

Zhuo, Q.Q., Ma, Y.Y., Gao, J., Zhang, P.P., Xia, Y.J., Tian, Y.M., Sun, X.X., Zhong, J., Sun, X.H., 2013, "Facile Synthesis of Graphene/Metal Nanoparticle Composites via Self-Catalysis Reduction at Room Temperature", Inorganic Chemistry, Vol. 52, pp. 3141-3147. 